\title{
Injectable Fillers for Volume Replacement in the Aging Face
}

\author{
Timothy M. Greco, M.D., F.A.C.S. ${ }^{1,2}$ Marcelo B. Antunes, M.D. ${ }^{1}$ Seth A. Yellin, M.D. ${ }^{3}$ \\ 1 Division of Facial Plastics and Reconstructive Surgery, Department of \\ Otorhinolaryngology-Head and Neck Surgery, University of \\ Pennsylvania, Philadelphia, Pennsylvania \\ 2 Eastern Cosmetic Surgery Institute, Bala Cynwyd, Pennsylvania \\ ${ }^{3}$ Division of Facial Plastic Surgery, Emory Healthcare; Emory Facial \\ Center; and Department of Otolaryngology-Head and Neck Surgery, \\ Emory University, Atlanta, Georgia \\ Facial Plast Surg 2012;28:8-20. \\ Address for correspondence and reprint requests Timothy M. Greco, \\ M.D., F.A.C.S., Eastern Cosmetic Surgery Institute, 2 Bala Plaza, Suite \\ 15, Bala Cynwyd, PA 19004 (e-mail: timg@drgrecoface.com).
}

\author{
Abstract \\ Keywords \\ - aging face \\ - volume loss \\ - hyaluronic acid \\ - calcium \\ hydroxylapatite \\ - poly-l-lactic acid
}

In recent years, there has been a better understanding of the aging process. In addition to changes occurring in the skin envelope, significant changes occur in the subcutaneous fat and craniofacial skeleton. This has led to a paradigm shift in the therapeutic approach to facial rejuvenation. Along with soft tissue repositioning, volumizing the aging face has been found to optimize the result and achieve a more natural appearance. Early in the aging process, when there has not been a significant change to the face requiring surgical intervention, fillers alone can provide minimally invasive facial rejuvenation through volumizing. Multiple injectable soft tissue fillers and biostimulators are currently available to provide facial volume such as hyaluronic acid, calcium hydroxylapatite, poly-l-lactic acid, polymethyl methacrylate, and silicone. A discussion of the morphological changes seen in the aging face, the properties of these products, and key technical concepts will be highlighted to permit optimum results when performing facial volumizing of the upper, middle, and lower thirds of the face. These fillers can act as a dress rehearsal for these patients considering structural fat grafting.

\section{Anatomy and Physiology of the Aging Face}

The soft tissue envelope of the face can be described as a series of layers: skin, subcutaneous fat, superficial muscular aponeurotic system, deep fat, and muscles of facial expression. This soft tissue envelope encompasses the craniofacial skeleton. In the past, a poor understanding of the effects of aging on these structures, particularly the loss and redistribution of facial volume that occurs with the passage of time, often resulted in suboptimal outcomes when facial rejuvenation procedures were performed. In recent years, contributions from Pessa ${ }^{1}$ and Rohrich ${ }^{2,3}$ and others have significantly improved our understanding of the aging face.

A predictable sequence of age-related changes of the face is first noticed in the third decade of life. These changes are reflected in all of the anatomic layers, particularly the skin, fat compartments, and the facial skeleton. The brows appear to descend, the skin of the face becomes lax, pseudoherniation of the orbital fat in the eyelid region occurs, and hyperfunctional rhytids such as frown lines occur and nasolabial folds become more prominent. Midfacial structures appear to descend along with noticeable tissue atrophy, further increasing the nasolabial fold prominence and creating a skeletonization of the lower eyelid. Jowls appear and submental fat accumulates along with the formation of platysmal bands. The progression of these events is not uniform and depends upon multiple factors.

The skin changes in the aging process are due to intrinsic and extrinsic factors. ${ }^{4}$ Intrinsic factors refer to changes related to the effects of time and are primarily determined by the genetics of the individual. The extrinsic factors are related to the effects of the environment such as sun exposure, smoking, significant weight loss, stress, systemic illness, and even
Issue Theme Management of the Lower Third of the Face and Neck; Guest Editor, Phillip R. Langsdon, M.D., F.A.C.S.
Copyright @ 2012 by Thieme Medical Publishers, Inc., 333 Seventh Avenue, New York, NY 10001, USA. Tel: +1(212) 584-4662.
DOI http://dx.doi.org/ $10.1055 / \mathrm{s}-0032-1305786$. ISSN $0736-6825$. 
smiling habits. ${ }^{5}$ As one ages, there is thinning of the epidermis with the basal cells displaying a wide variability in both shape and size. ${ }^{6}$ However, the most consistent change of the aged skin is effacement of the epidermal-dermal junction. ${ }^{7}$ Other common findings are thinning of the immediate subcutaneous fat and loss of organization of elastic fibers and collagen resulting in the loss of elastic properties of the skin. ${ }^{8}$ In addition to age-related laxity, mottled and hyperpigmented skin associated with lymphocytic infiltration and an increased number of melanocytes is often seen in conjunction with coarse wrinkles and a rough skin surface. ${ }^{9,10}$

Deep to the skin the facial fat exists in distinct compartments. Using dye injections, 10 facial fat compartments have been identified: these include the nasolabial, medial, and middle cheek; central forehead; middle temporal and lateral temporal-cheek; the superior, inferior, and lateral orbital compartments; and the jowl compartment. ${ }^{2}$ Between these compartments are dense septal fascial condensations. ${ }^{3}$ These septa arise from the superficial fascia and insert into the dermis of the skin, usually carrying a dense vascular network. These boundaries form the "retaining system" of the face. ${ }^{11,12}$ The complex relationship of the fat compartments and retaining ligaments, coupled with the fact that the compartments do not age confluently, helps to explain the soft tissue changes that occur in the aging face. It is the relative positional change of fat compartments (shearing effects), as well as fat atrophy (periorbital, temporal and buccal fat pads) and fat hypertrophy (submental and nasolabial fat), which helps to account for the volume changes seen in the aging face. The final piece to the aging face puzzle comes from the changes seen in the craniofacial skeleton. Pessa ${ }^{1}$ described the clockwise rotation of the maxilla in relation to the cranium with aging. This, along with a relative contraction of the bony skeleton and the changes in the glabella and maxillary angles seen with the passage of time, explain the loss of skeletal support and its effect on the overlying soft tissues.

When rejuvenating the aging face, surgical soft tissue repositioning of the ptotic tissues must be accompanied by volumizing of the face to optimize the surgical result and achieve a more natural appearance. In the third, fourth, and even fifth decades, when skin laxity may not be a major concern and volume loss is not as severe, fillers alone can provide a minimally invasive technique for facial rejuvenation.

Hyperfunctional rhytids are also seen in the aging process of the face. The horizontal furrows in the forehead are caused by repeated action of the frontalis muscle. The rhytids in the glabella include the horizontal (procerus muscle) and vertical furrows (corrugator muscle). Around the eyes, the hyperactivity of the orbicularis oculi muscle will create the crow'sfeet laterally. In the midface, the zygomaticus minor and major, along with other lip elevator muscles, will make the nasolabial fold more pronounced due to repeated contraction with smiling. In the lower third of the face, hyperfunctional rhytids can be seen primarily in the perioral region, particularly in the upper and lower lips due to repeated contraction of the orbicularis oris. In addition, loss of volume to the lip complex can accentuate the aging of the perioral region. Treatment with neurotoxins not only improves hyperfunc- tional rhytids but also helps with facial reshaping along with fillers.

\section{Fillers and Volumization of the Face}

Multiple products are currently Food and Drug Administration (FDA) approved to be used to provide facial volume. As in any situation in which a drug has one approved use, off-label use is at the discretion and judgment of the prescribing physician. In the case of facial fillers, the FDA-approved indications are often limited to a specific facial feature (most commonly the nasolabial fold), although, based on accumulated clinical experience, it has been shown that specific products are useful when filling other facial areas as well. However, there are certain areas of the face that intrinsically have a greater risk when injecting fillers, most notably the glabella and nasal tip, and no product should be considered completely safe if one chooses to inject these sites. The substances most commonly used for facial volumizing are hyaluronic acid (HA), calcium hydroxylapatite (CaHA), poly-llactic acid (PLLA), polymethyl methacrylate (PMMA), silicone, and autologous fat. Both bovine and human collagen have become historic due to the success of these other fillers. Autologous fat is biocompatible, lacks toxicity, and has a low cost and a very low incidence of complications, which is why it is considered by many as an ideal filler. However, the greatest challenge of structural fat grafting is in maintaining its viability, and controversy exists in the literature regarding its durability. The use of fat for volume replacement will be discussed in another article in this issue.

\section{Hyaluronic Acid}

HA is a naturally occurring glycosaminoglycan that composes the extracellular matrix of connective tissue and is found in humans as well as in all living species. ${ }^{13}$ It consists of a polymer comprised of alternating D-glucuronic acid and N-acetyl-D-glucosamine monosaccharide cross-linked into a long unbranched chain. Its molecule is hydrophilic, which leads to tissue hydration and turgor. A gram of HA can hold 1000 times its weight in water. ${ }^{14}$ In the skin this property provides support and creates volume. As the skin ages, the content of HA decreases and this decrease directly correlates with decreased moisture and increased rhytid formation. ${ }^{15}$

Naturally occurring HA is rapidly degraded with a half-life of $\sim 12$ to 24 hours. Exogenous HA has a shorter half-life of 1 to 2 hours. $^{16}$ Therefore, the manufacturing goal is to create an HA with increased tissue residency and elasticity while maintaining its biocompatible nature. The process of crosslinking HA molecules accomplishes this goal. This can be accomplished with butanediol diglycidyl ether (BDDE), divinyl sulfone, biscarbodiimide, or 1,2,7,8-diepoxyoctane, depending on the product. The degree of cross-linking will enhance the persistence of the HA filler, but excessive cross-linking may reduce the biocompatibility of the filler, causing foreign-body reaction and encapsulation. ${ }^{17}$ Crosslinking will also change the rheological properties of the gel. Harder gels, which consist of a greater degree of cross-linking, are more difficult to inject and create more discomfort when 
injected; however, they are better able to resist the dynamic forces associated with muscle movement and potentially have a longer duration of action. Moreover, they may feel firmer under the skin and are better suited for volumizing deeper folds in thicker-skinned patients. On the other hand, softer gels, which have a lesser degree of cross-linking, are easier to inject and more comfortable for the patient. They feel softer under the skin and are better suited for the thinner skin and finer rhytids of the central face such as the periorbital and perioral regions.

Currently, all HA fillers are derived from the fermentation of Streptococcus equi bacterium, which are referred to as nonanimal stabilized HA, or NASHA. The products available in the United States are: Restylane ${ }^{\mathrm{TM}}$ (Medicis Aesthetics, Inc. Scottsdale, AZ), Juvederm Plus ${ }^{\mathrm{TM}}$ (Allergan, Inc. Irvine, CA), Juvederm Ultra Plus ${ }^{\mathrm{TM}}$ (Allergan, Inc. Irvine, CA), Perlane ${ }^{\mathrm{TM}}$ (Medicis Aesthetics, Inc. Scottsdale, AZ), Elevess ${ }^{\mathrm{TM}}$ (Anika Therapeutics, Inc. Bedford, MA), and Prevelle ${ }^{\mathrm{TM}}$ (MentorWorldwide, LLC, Santa Barbara, CA). The most popular agents are Restylane ${ }^{\mathrm{TM}}$ and Perlane ${ }^{\mathrm{TM}}$ and the Juvederm families, and for the purpose of this discussion the authors will limit the discussion to these agents. ${ }^{18-21}$

Restylane $^{\mathrm{TM}}$ and Perlane ${ }^{\mathrm{TM}}$ were approved by the FDA for facial folds and wrinkles in 2003 and 2007, respectively. They are a particulate form of NASHA cross-linked with BDDE. The only difference between the two products is the particle size, with Perlane ${ }^{\mathrm{TM}}$ being twice as large as Restylane ${ }^{\mathrm{TM}}$ particles. Juvederm Ultra ${ }^{\mathrm{TM}}$ and Juvederm Ultra Plus ${ }^{\mathrm{TM}}$ are also crosslinked with BDDE and are the only nonparticulate form of HA available in the United States. Muscular activity seems to play a role in the longevity of HA's clinical result as studies have found that the concurrent injection of botulinum toxin with HA into the glabella will extend particulate NASHA (Restylane ${ }^{\mathrm{TM}}$ ) longevity to $\sim 7$ to 9 months as opposed to $\sim 4$ months without. 22,23

Due to the intrinsic properties of $\mathrm{HA}$, self-limited injection site edema and discomfort are expected. However, potential complications and adverse reactions of HA fillers are minimal. They are mainly injection-related and tend to be self-resolving. Of note is the report of two cases of injection site necrosis ${ }^{24}$ and the reports of granuloma-like foreign body reaction..$^{25}$ Hyaluronidase, the enzyme that breaks down HA, creates a degree of reversibility for HA treatment, which may be beneficial if overcorrection or a complication from the material has occurred. ${ }^{26}$

\section{Calcium Hydroxylapatite}

$\mathrm{CaHA}$ is a mineral present in bone and teeth. As a naturally occurring substance, it is inherently biocompatible and is metabolized into calcium and phosphate. Radiesse ${ }^{\circledR}$ is an injectable filler material composed of microspheres of CaHA (25 to $45 \mu \mathrm{m}$ ) at $30 \%$ concentration suspended in a gel composed of water, glycerin, and sodium carboxymethylcellulose. This formulation provides a 1:1 volumetric correction without the need for overcorrection. Once injected, the gel is slowly absorbed over a period of months. During this interval, there is ingrowth of fibroblasts into the scaffold of microspheres that will gradually replace the carrier gel. As these cells replace the gel, they will increase collagen synthesis, which will anchor the microspheres in place. In soft tissues, it does not induce osteogenesis. The microspheres, stabilized at the injection site by new collagen formation, will then slowly be reabsorbed over several months. ${ }^{27-30}$

In 2006, Radiesse ${ }^{\mathrm{TM}}$ was approved by the FDA for correction of facial wrinkles or folds and for the correction of the sequelae from HIV-related lipoatrophy. Prior to 2006, it was already used for vocal cord augmentation and urinary incontinence and as a radiographic marker. Two studies comparing Radiesse $^{\mathrm{TM}}$ with HA fillers such as Restylane $\mathrm{T}^{\mathrm{TM} 31}$ and Juve$\operatorname{derm}^{\mathrm{TM}}$ and Perlane ${ }^{\mathrm{TM}}{ }^{32}$ reported "more effective" or "improved" results with Radiesse ${ }^{\mathrm{TM}}$.

The longevity of Radiesse ${ }^{\mathrm{TM}}$ depends on the patient's age and metabolism and also on the relative dynamics of the injected area. ${ }^{33}$ Overall, the effect is expected to remain almost unchanged for 12 months, and after 12 to 18 months the volume changes begin to fade, but may be noted up to 24 months in some instances. ${ }^{34}$

The complication rates are low and are most often related to injection technique. Pain, redness, and swelling are frequent and temporary. The discomfort with injection of CaHA can be lessened by mixing the product with lidocaine and/or performing regional anesthesia (infraorbital and/or mental nerve blocks). It is best to massage this product after placement to evenly distribute the CaHA and carrier, which will promote fibroblast ingrowth more uniformly. The material may be palpable after injection for a period that ranges from 2 to 3 months. ${ }^{35}$ Nodules and granulomas have been described. Nodularity occurs when the material is injected too superficially into the dermis instead of the proper subdermal plane. In these circumstances, the white nodules should be punctured with a 18-gauge needle or a No. 11 blade immediately, before there is a chance for the microspheres to adhere to the adjacent stroma. ${ }^{35}$ This product should not be injected into the lips or glabella.

\section{Poly-L-Lactic Acid}

PLLA is a synthetic material from the $\alpha$-hydroxyl-acid family, similar to absorbable suture materials. PLLA is marketed as Sculptra ${ }^{\mathrm{TM}}$, which is a biostimulator rather than a traditional filler, which provides immediate volumetric improvement. As a biostimulator, PLLA promotes volumizing through production of collagen and the vascularization of native collagen. ${ }^{36}$ PLLA comes as a freeze-dried powder combined with sodium carboxymethylcellulose and nonpyrogenic mannitol. Proper hydration of the product is of paramount importance. Not only does adequate hydration prevent clogging of the needle during injection, but more importantly, the production of subcutaneous nodules. The PLLA powder is premixed with $5 \mathrm{~mL}$ of sterile water and allowed to reconstitute for at least 24 hours at room temperature. ${ }^{37}$ Some authors recommend using more than $5 \mathrm{~mL}$ of water to further reduce the risk of subcutaneous nodularity. ${ }^{38-40}$ The senior authors use $6 \mathrm{~mL}$ of sterile water to hydrate the product with the addition of $2 \mathrm{~mL}$ of lidocaine with epinephrine 1:100,000 added immediately before injection. The reconstituted vial should be swirled but not shaken. This results in a total volume of $8 \mathrm{~mL}$ of rehydrated PLLA per vial. This dilution, as well as 
gentle agitation of syringes before injection, helps to keep the particles of the product in suspension, which prevents difficulty with injection and postinjection sequelae (i.e., subcutaneous nodules).

Sculptra ${ }^{\mathrm{TM}}$ was recently approved for aesthetic soft tissue augmentation adding to its previous FDA indication for soft tissue augmentation secondary to HIV-related facial lipoatrophy. The product is not recommended for perioral treatment.

Patient counseling is especially important when using PLLA due to its delayed effect. Patients requiring a more immediate result are not suitable for this product alone. HA and CaHA fillers may be injected along with PLLA at the same treatment session to provide an immediate result. Patients usually require more than one treatment, with three treatments spaced 6 weeks between injections constituting the most common clinical scenario. In some cases, several additional treatments may be necessary over a 4- to 6-month period to obtain optimal volumization. Collagen production usually starts in 6 to 8 weeks ${ }^{41}$ following injection, with type 1 collagen continuing to form for up to 9 to 12 months after the last treatment. ${ }^{36}$ The volumetric benefits last $\sim 2$ to 3 years. ${ }^{42}$ Meanwhile, PLLA particles start to be reabsorbed around 6 months and disappear by 9 months. ${ }^{43}$

The most common adverse effects are injection related. Small, palpable, inconspicuous subcutaneous nodules, as well as visible nodules, can result from uneven distribution, superficial placement, or improper reconstitution of the product. ${ }^{44}$

\section{Polymethyl Methacrylate}

PMMA has been used for years as bone cement. Artefill ${ }^{\mathrm{TM}}$ (Suneva Medical, Inc., San Diego, CA) is a third-generation PMMA purified to achieve microsphere sizes between 30 and $50 \mu \mathrm{m}$. Smaller particles are easily removed by phagocytosis and have a higher likelihood of creating granuloma formation, and larger ones make the product more difficult to inject. The PMMA microspheres are suspended in a modified bovine collagen solution, which has been processed to remove the more antigenic portion of the molecule. However, unlike the previously described products, Artefill ${ }^{\mathrm{TM}}$ requires a skin test prior to treatment due to a $3 \%$ prevalence of hypersensitivity to bovine collagen seen in the general population. ${ }^{45}$ The collagen solution keeps the spheres from clumping together, and during its absorption, fibrin and new collagen deposition takes its place. At the end of this process, the augmented volume is $\sim 20 \%$ PMMA and $80 \%$ autologous connective tissue. ${ }^{46}$

Artefill $^{\mathrm{TM}}$ is FDA approved as a permanent injectable filler only for the nasolabial folds. This property should be discussed with the patient and taken into consideration before selecting additional areas for injection. It is best suited for placement in the deep dermis and relatively contraindicated in areas of thin skin such as the lips. Some authors recommend the use of a temporary filler prior to the use of PMMA so the patient can "test-drive" the aesthetic changes. ${ }^{47}$ Similar to PLLA, full volumetric correction requires several procedures, with follow-up appointments necessary for further augmentation and refinement.

Complications arising from Artefill ${ }^{\mathrm{TM}}$ injection are often related to injection technique. Visible or palpable dermal nodules may occur from superficial injection and can be excised. If excision becomes necessary, the entire lesion should be removed to avoid continued fibroblast stimulation. ${ }^{46}$ Hypersensitivity (lower than with pure collagen fillers $)^{43}$ and granuloma formation ${ }^{48,49}$ have also been reported.

\section{Silicone}

Injectable silicone is a popular yet controversial product used for volumizing the face. Its chemical constituents are silicon, oxygen, and methane. It is best used in its most pure form (Silikon $1000^{\mathrm{TM}}$ [Prima Pharm, Inc., San Diego, CA]). ${ }^{50}$ The use of this product as a volumizer is off-label, with the only FDAapproved use being restricted to severe retinal detachment. This substance can be used as a permanent filler. Studies of injectable silicone in the face are variable in regards to results and complications. The time for late complications to present themselves may be up to 8 to 10 years. ${ }^{51}$

This product is best injected using the microdroplet method. This involves placing small quantities ( 0.01 to $0.03 \mathrm{~mL}$ ) of the product into the subcutaneous tissue. Overcorrection as well as superficial intradermal injection must be avoided. Proper placement is in the deep dermis or preferably in the subdermal plane, due to the fact that part of the correction is a late fibroblast response to the injected silicone particle. ${ }^{52}$

\section{Treatment of the Aging Face}

As elucidated in the section on anatomy and physiology of the aging face, treatment of the aging face has undergone a significant paradigm shift in the past decade. In addition to tightening and repositioning of the skin envelope and superficial aponeurotic system with various face-lifting techniques, the aging face is also being rejuvenated with volume. Instead of making the "envelope" smaller, the "letter" inside the envelope is being made larger. Coleman ${ }^{53}$ and others have led the way by using autologous fat as a means of volumizing the entire face often to the exclusion of other rejuvenation techniques. The truth is that there is a happy medium that should be struck between the two processes to create a natural-appearing and rejuvenated face.

Historically, fat transfer was the first material used for facial volumizing. However, this technique often requires some form of anesthesia (general or conscious sedation), may create donor site issues, and suffers from unreliable graft take. Therefore, other techniques have been developed using off-the-shelf fillers and/or biostimulators. These products are injected into the face in a minimally invasive fashion, are readily available, and avoid donor site issues. However, the cost of the products, the duration of the filler in vivo, and the need to select the appropriate material and technique to optimize the aesthetic result make individualizing a patient's care plan critical. Additionally, as new injectable products are developed, it is incumbent on the physician to stay current and adapt their approach to volumizing the face.

For sake of discussion, the face will be divided into upper, middle, and lower thirds. Although this discussion involves regional concepts of volumizing (i.e., temples, cheeks, etc.) the face should be diagnosed and treated as a whole. Given the 

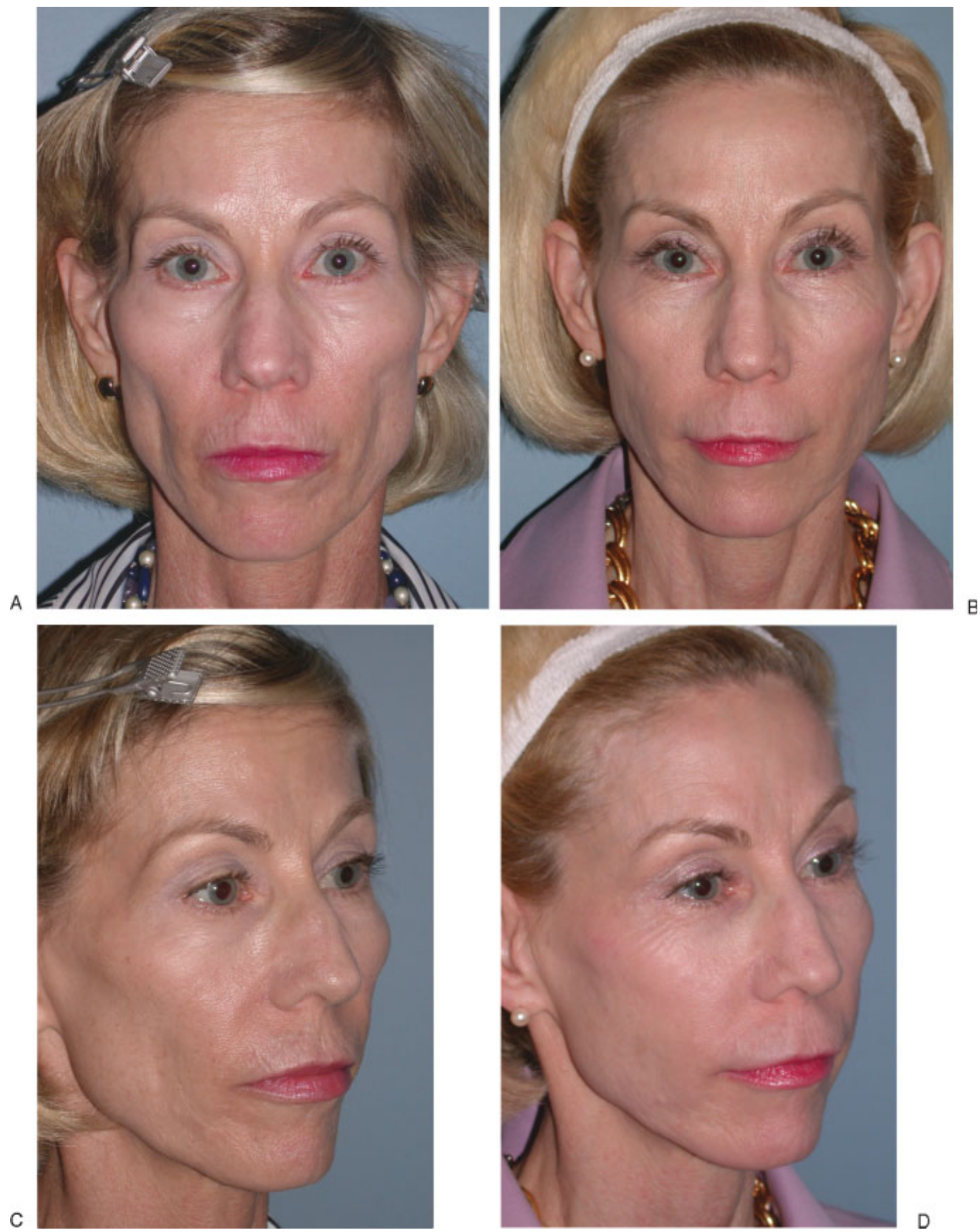

B

Figure 1 Volumization of the temporal area. ( $A$ and C) Pre- and (B and D) postinjection of $8 \mathrm{~mL}$ (one vial) of poly--lactic acid on each temple (patient also received $48 \mathrm{~mL}-$ six vials-to the malar region). (Picture courtesy of Timothy M. Greco, M.D.)

current landscape of injectable products, the preferences and specific techniques utilized by the senior authors (T.M.G. and S.A.Y.) will be shared to provide a therapeutic recipe to optimize clinical outcomes.

\section{Volumizing the Upper One-Third of Face}

The two areas of the upper one-third of the face that in our hands are most amenable to volumizing are the temples and the infrabrow regions. Deflated, hollow temples have a profound effect on the aging face. Not only does this appearance denote senescence but also a gaunt unhealthy appearance. Volumization of the temples can have the collateral benefit of providing a gentle elevation of the tail of the brow by reinflating the temporal fossa as well as its primary benefit of providing an overall fullness or roundness to the face.

Our product of choice for volumizing the temple is PLLA. Our dilution was previously mentioned. The base of the 
temple depression is identified and a $1-\mathrm{mL}$ depot injection is placed below the deep temporalis fascia. Several $0.5-\mathrm{mL}$ injections are then performed around the primary depot injection in a rosette fashion to volumize the temple depression more peripherally. The injections are carried up to the region of the temporal fusion line. After a 6 - to 8 -week period, postprocedural pictures are obtained and a second or third session of PLLA is performed until adequate volumization is accomplished (-Fig. 1).

Another area of deflation that occurs in the upper onethird of the face is the infrabrow region. This deflation of the infrabrow and retro-orbicularis oculi fat pad is partly responsible for brow descent seen with aging. When performing a minimally invasive brow-lift, the results of neurotoxin injections into the corrugators, procerus, and vertical fibers of the orbicularis oculi muscle can be accentuated by volumizing the infrabrow region. Also, in those patients with brow asymmetry despite neurotoxin injections, inflation with accompanying modest elevation of the ptotic brow can provide additional improvement in symmetry. This technique involves injection of a non-animal-derived HA just below the inferior brow hairs. This injection may be subcutaneous and/ or down to the supraorbital rim (similar to tear trough placement) and is performed in a linear threading fashion. It is important to identify the supraorbital notch and stay lateral to the neurovascular bundle.

\section{Volumizing the Midface}

The midface plays an integral role in the aesthetics of the aging face. Volumizing this region not only affects the midface proper but also provides a lifting vector to the lower face, particularly the nasolabial folds and to a lesser extent the jowls. To understand the treatment of the midface one needs to understand the aging characteristics of this area. The aging of the midface skeleton is reflected in the overlying soft tissues. It has been shown that a change in the orbitomaxillary region leads to changes in the overlying soft tissues creating the aged appearance of the midface. ${ }^{54}$ The bony changes that occur involve an increase in size of the orbits in addition to a decrease in size of the medial maxilla and corresponding expansion of the pyriform aperture. Pessa ${ }^{1}$ along with Shaw and $\mathrm{Kahn}^{55}$ have found that the change in the midface with aging results in greater acuteness of the important structural angles of the face, including the glabella and maxillary angles. These changes can be explained by a relative clockwise rotation seen between the facial skeleton and the cranium. These changes are transmitted to the overlying soft tissues and help explain the characteristic aging seen in the face. Finally, another significant change occurring in the midface is the change in the orbital shape particularly due to an increase in the superior medial and inferior lateral distance of the bony orbit. This change contributes to senile ectropion, scleral show, and the tear trough deformity seen with aging. All of these changes can be modified by volumizing the midface and can result in an ensuing improvement in position of the soft tissue envelope of the midface and to some extent of the lower face as well.

\section{Tear Trough Treatments}

In addition to the change in the orbital aperture with aging, the tear trough or nasojugal deformity is created by the descent of the malar fat pad inferiorly and medially. These changes lead to skeletonization of the inferior orbital rim, apparent lengthening of the lower eyelid, and generalized midfacial flattening, which results in a face that appears tired and aged. Additionally, pseudoherniation of the lower eyelid periorbital fat may accentuate these changes leading to further undesirable contour of the midfacial soft tissue envelope. Dark circles under the eyes are multifactorial but will be accentuated by a deep tear trough deformity. Volumizing the tear trough deformity is often the most aesthetically powerful nonsurgical intervention available to rejuvenate a face. Our preferred method for volumization of the tear trough is with a non-animal-derived particulate HA (Restylane $^{\mathrm{TM}}$ ). Particulate HA works best in our hands as it creates a soft and natural correction that lasts for up to 18 months with minimal risk. Additionally, the product stays in place and does not clump together leading to a sausagelike deformity, which can sometimes occur with nonparticulate HA. The technique involves a combination of microdroplet deposition and linear threading along the orbital rim just above the periosteum, being careful to remain below the orbicularis oculi muscle. This prevents contour abnormalities as well as the Tyndall effect (a bluishgray discoloration that occurs when a clear gel such as HA is injected too superficially). The treatment should be extended temporally to include the hollowness frequently seen in the region of the lateral orbital rim. Undertreatment and gentle soft tissue molding are the key treatment points in this region. Another benefit of HA injections to the tear trough is that there may be a subtle correction in mild lid retraction seen with aging. An infraorbital nerve block can

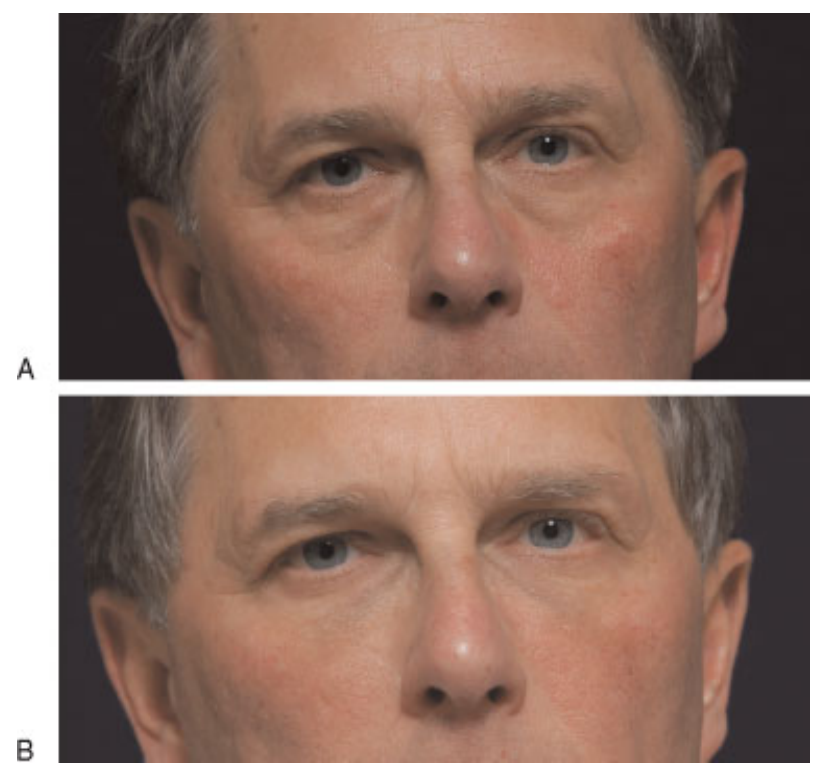

Figure 2 Volumization of tear trough area. (A) Pre- and (B) postinjection of $2.4 \mathrm{~mL}$ of small-particulate hyaluronic acid. (Picture courtesy of Seth A. Yellin, M.D.) 
A

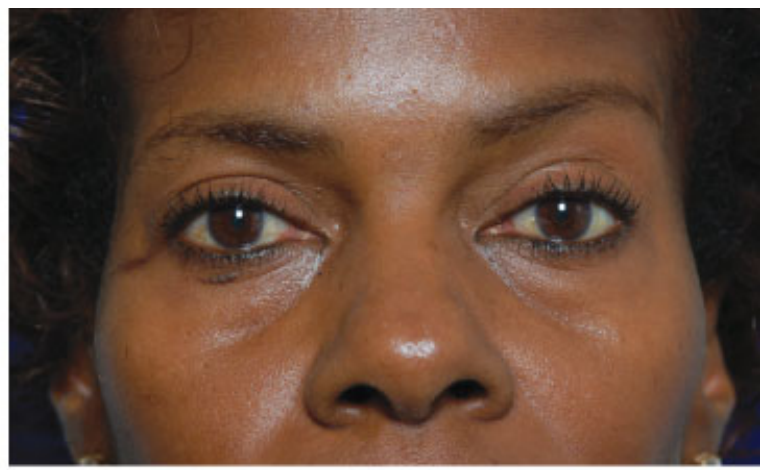

B

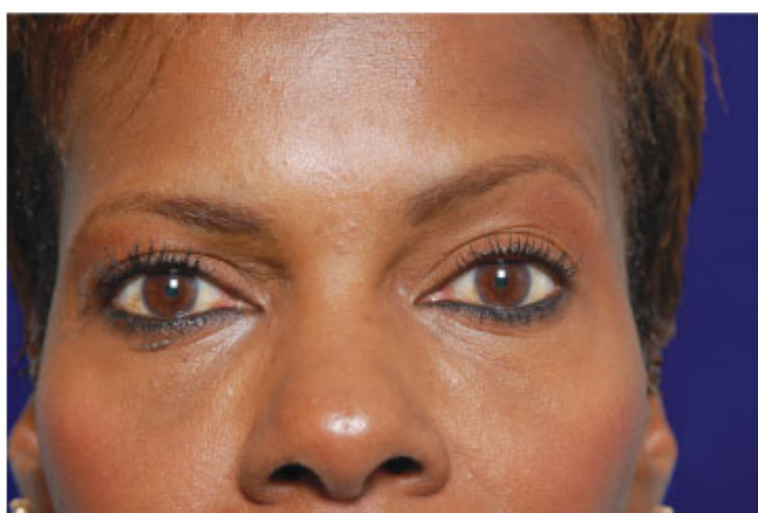

Figure 3 Volumization of tear trough area. (A) Pre- and (B) postinjection of $1 \mathrm{~mL}$ of small-particulate hyaluronic acid. (Picture courtesy of Seth A. Yellin, M.D.)

be used to enhance the patient's comfort, or one can use Restylane $^{\mathrm{TM}}$, which now is available premixed with lidocaine. Patients should be instructed to avoid nonsteroidal anti-inflammatory drugs, vitamin E, omega fish oils, and other herbal preparations that may contribute to bruising prior to this or any other facial injectable treatment. Afterward, the use of Arnica montana sublingually as well as topically may be used to reduce bruising. Additionally, the patient is instructed to gently mold the area with their index finger for 3 minutes, three times per day, for 3 days to smooth and distribute the material as it binds water and swells (-Figs. 2, 3, and 4).
Festoons of the lower eyelid-malar junction are another periorbital age-related deformity that may be successfully addressed with particulate HA fillers. Festoons are redundant folds of lax skin and sagging orbital and malar segments of orbicularis oculi muscle that hangs, in hammocklike fashion, from canthus to canthus when the face is upright. They develop over time in predisposed individuals due to the attenuation of the orbicularis oculi muscle and laxity of the attachments between the orbicularis and the deep fascia. Some patients cite a history of familial occurrence of these folds. Surgical treatment routinely focuses on addressing the redundant skin and orbicularis muscle via an extended subciliary lower eyelid blepharoplasty with a myomectomy of the redundant muscle. However, particulate HA fillers provide a nonsurgical treatment alternative that offers significant aesthetic improvement by building up the soft tissues of the malar area above and below the festoon. This technique effectively camouflages the skin and muscular redundancy for $\sim 18$ months, at which time repeat therapy is required to maintain the aesthetic benefit ( $\mathbf{- F i g . 5}$ ).

\section{Malar Augmentation}

Another area of the midface that benefits from volume is the cheek region, which includes the malar and submalar regions. Any of the fillers mentioned previously may be used for volumizing the cheeks, including HAs, CaHA, PLLA, and silicone. It is the opinion of the senior authors (T.M.G. and S.A.Y.) that CaHA and PLLA are the best for volumizing the malar regions. These products provide the most clinically noticeable volume with the least amount of product used. Injection involves a depot injection of product on the malar eminence and in the regions of greatest volume loss followed by deep subcutaneous fanning with cross-hatching creating a layering effect of product. Deeper injections require greater amounts of product and may increase the likelihood of vascular occlusion. Cross-hatching and cross-fanning helps to evenly distribute the filler throughout the cheek region. The use of a cheek implant sizer may make injection placement to the cheek easier to conceptualize. ${ }^{56}$ An infraorbital and zygomaticofacial nerve block with $1 \%$ lidocaine with epinephrine 1:100,000 can be helpful. This injection of the

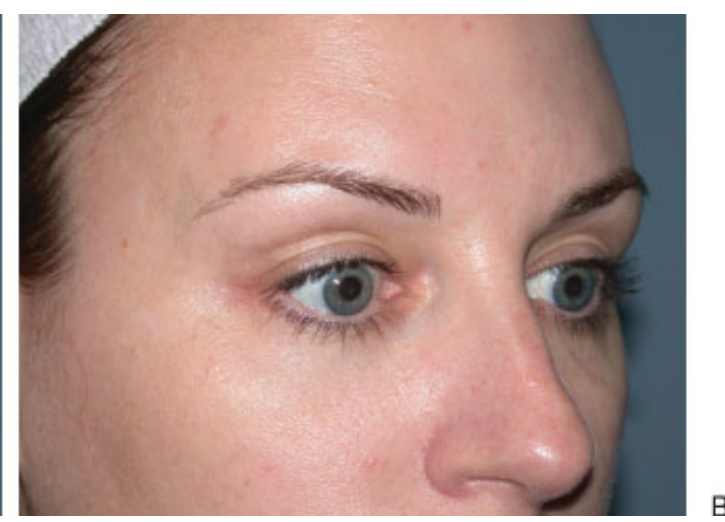
B

A

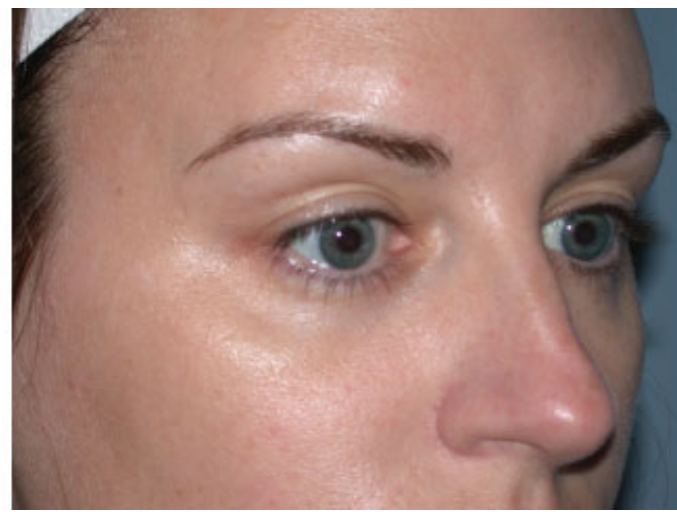

Figure 4 Volumization of tear trough area. (A) Pre- and (B) postinjection of $1 \mathrm{~mL}$ of small-particulate hyaluronic acid. (Picture courtesy of Timothy M. Greco, M.D.) 
A
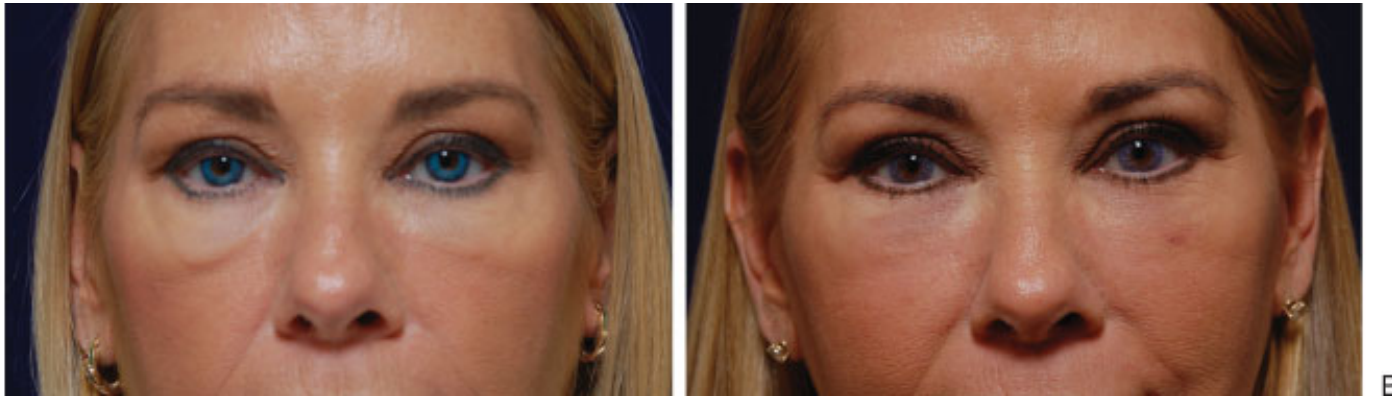

Figure 5 Volumization of festoons. (A) Pre- and (B) postinjection of $2 \mathrm{~mL}$ of small-particulate hyaluronic acid. (Picture courtesy of Seth A. Yellin, M.D.)

cheeks with volumizing of the midface can have a secondary collateral effect on the nasolabial fold and to a lesser extent on the jowls. Volumizing the submalar region can significantly improve the gaunt appearance associated with hollowness in this region, which is often seen with significant weight loss. Although many of the fillers previously mentioned may improve the submalar region, PLLA and nonparticulate HA (Juvederm UltraPlus ${ }^{\mathrm{TM}}$ ) administered in a cross-hatching fashion give a smooth, full appearance to this area (-Figs. 6 and 7).

Another unique area that can benefit from volumizing is the aging earlobe. As the earlobe ages it becomes atrophic, develops folds and wrinkles, and may become pendulous. The analogy is a grape becoming a raisin as it dehydrates. Not only does the ear become less aesthetically pleasing, earrings (particularly studs) may not sit well and the earring becomes ptotic in position. Occasionally the ear-piercing hole enlarges, which contributes to malposition of the earring. Volumizing the earlobe with HA improves all aspects of the aging earlobe. It also improves the posture and support of the earlobe so that once the earring is placed back into the lobule, the earring presents better. A fanning technique in a 360-degree pattern around the piercing can help rejuvenate the ear. Manual molding creates an even distribution of the HA throughout the earlobe ( $\mathbf{- F i g . 8}$ ). Fillers placed in static regions of the face (i.e., earlobes) will last much longer than those placed in dynamic areas.

\section{Volumizing the Lower Face}

The lower one-third of the face is also susceptible to significant bone and soft tissue volume loss. The aesthetic consequences of this volume loss are accentuated by the descent of the midfacial soft tissues inferiorly and medially, leading to prominence of the nasolabial folds, also known as "melolabial folds," and marionette folds, also referred to as "labiomandibular folds." Both are prominent features of the aging face.
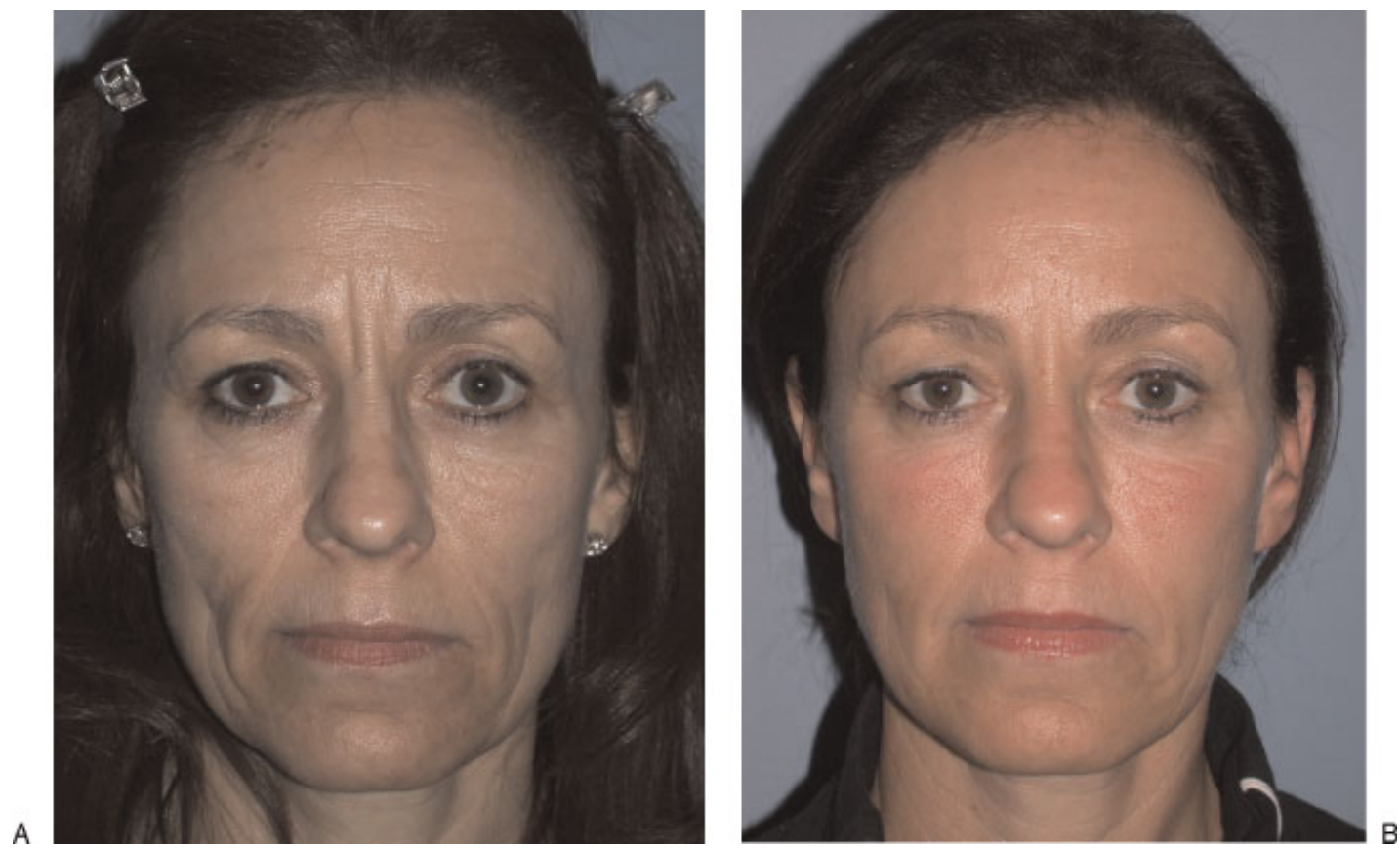

Figure 6 Volumization of malar area. (A) Pre- and (B) postinjection of $56 \mathrm{~mL}$ (7 vials) of poly-l-lactic acid (patient also received $0.4 \mathrm{~mL}$ of small-particulate hyaluronic acid to the glabella. Botulinum toxin was injected to the glabella and crow's-feet). (Picture courtesy of Timothy M. Greco, M.D.) 
A
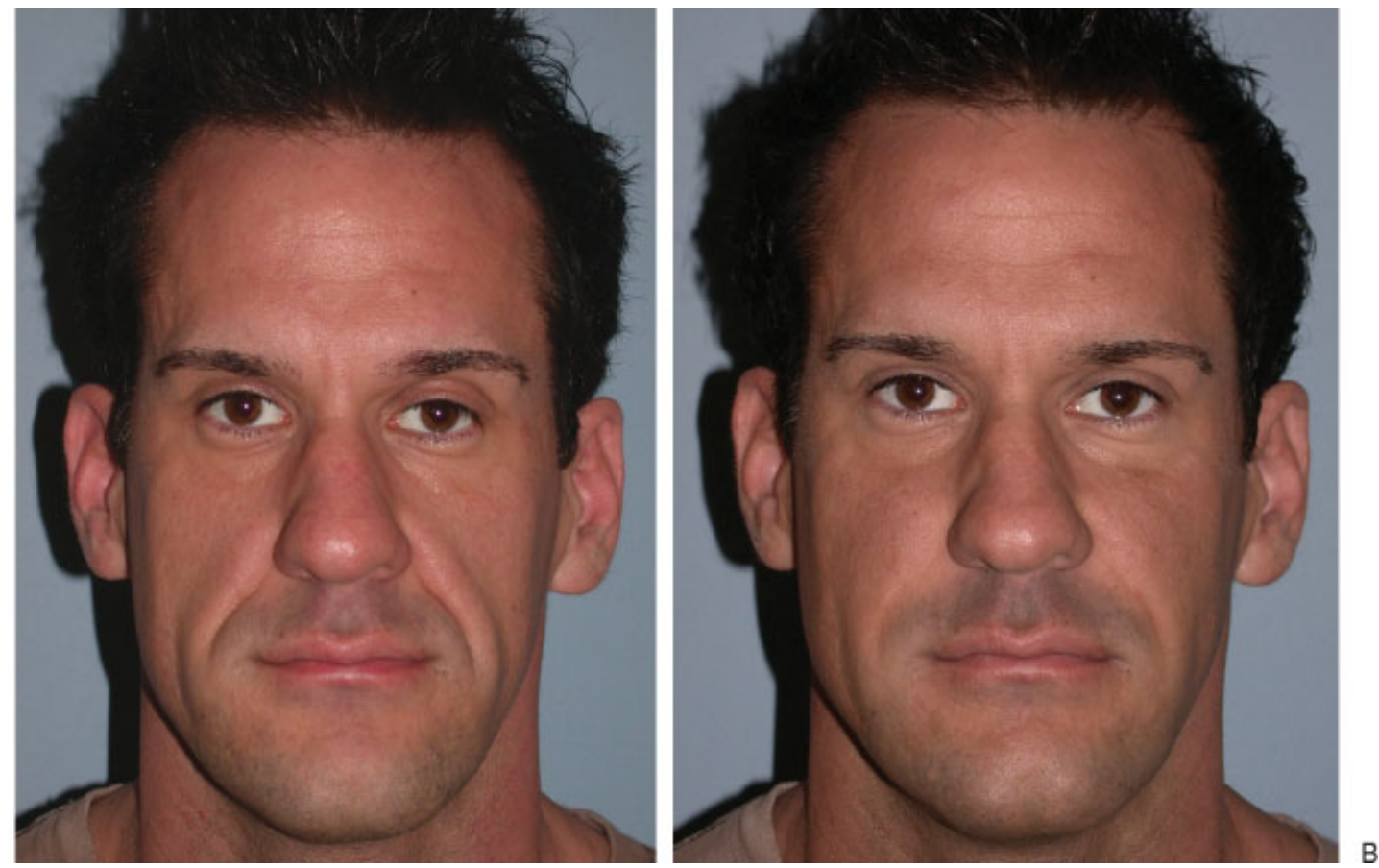

Figure 7 Volumization of malar area. (A) Pre- and (B) postinjection of $16 \mathrm{~mL}$ (two vials) of poly--lactic acid and $8 \mathrm{~mL}$ of calcium hydroxylapatite. (Picture courtesy of Timothy M. Greco, M.D.)

Volumizing these structures greatly enhances the appearance of the perioral area and counters the effects of soft tissue ptosis. This leads to generalized facial aesthetic improvement (-Fig. 9). Cross-hatching and linear threading of HAs or CaHA are the preferred products used in these areas. Greco and Elenitsas ${ }^{5}$ showed cross-hatching in the nasolabial fold can improve their appearance by placing HA medially in the region where the dermal attachments become dense, which corresponds to the medial aspect of the nasolabial fat compartment. Volumizing the marionette folds along with injections of neurotoxin to the depressor anguli oris can help improve the downward posture of the oral commissures. PLLA may also be used to augment the nasolabial folds but usually is not used for the marionette area, as it may lead to visible subcutaneous nodules in this area.
The lips occupy an important central area of the lower face, and aging can significantly alter their structure. Atrophic changes of the lips seen with aging include loss of the vermilion border and generalized flattening of lip architecture, loss of volume, and inversion of the red lip with resultant loss of poutiness and a youthful lip posture. Volumizing the lip can improve all of these issues. However, one word of caution: given the currently available soft tissue fillers, the filling of vertical lip rhytids should address the deepest lines using very judicious volumes of a nonparticulate HA. Very fine lines are best not treated with fillers but may respond well to perioral Botulinum toxin therapy or skin resurfacing. After a dental nerve block is achieved, a nonparticulate HA (Juvederm Ultra ${ }^{\mathrm{TM}}$ ) is injected using a linear threading technique. Injection on the red portion of the lip 2 to $3 \mathrm{~mm}$ inside the

A
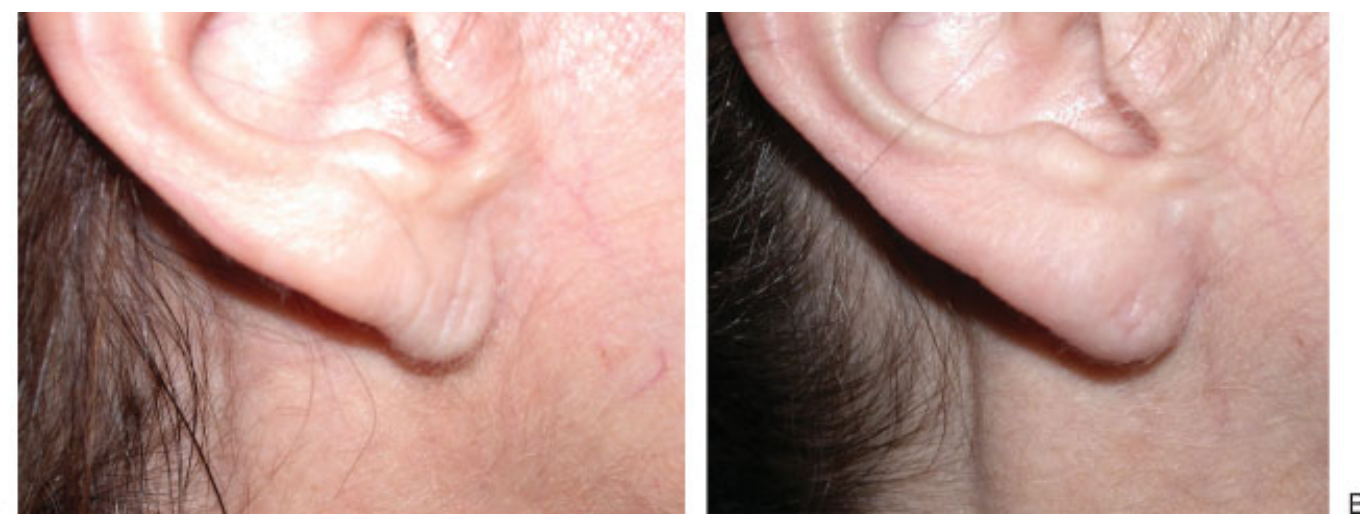

Figure 8 Volumization of earlobe. (A) Pre- and (B) postinjection of $1 \mathrm{~mL}$ of small particulate hyaluronic acid. Note that fillers in regions without significant muscular activity can persist for many years. (Picture courtesy of Timothy M. Greco, M.D.) 
A
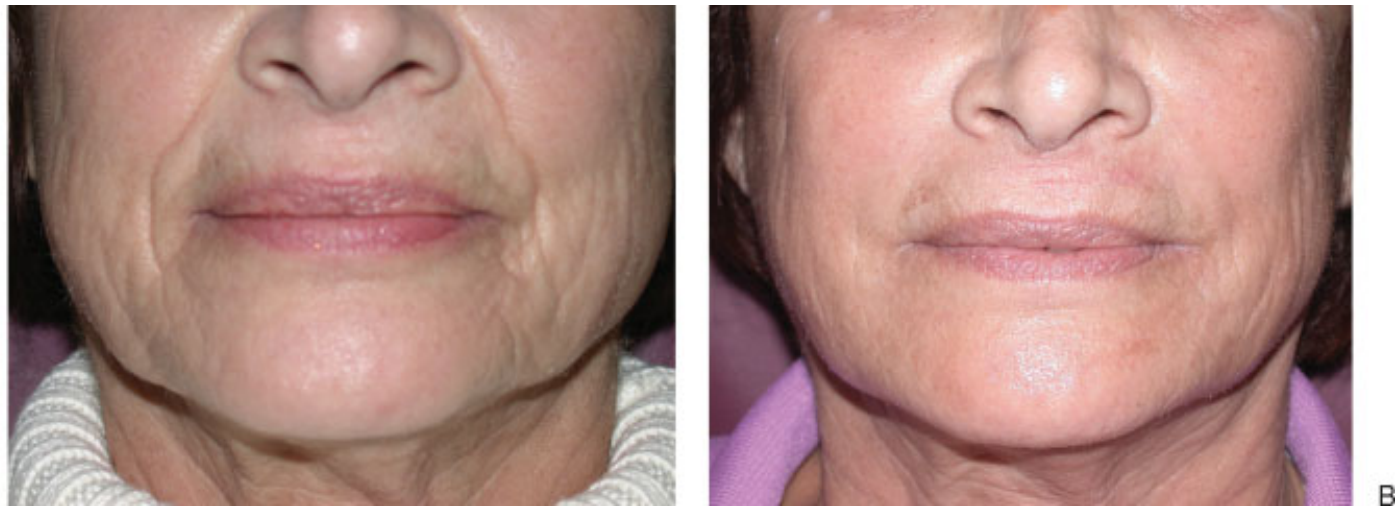

Figure 9 Volumization of the lower third of the face. (A) Pre- and (B) postinjection of $6 \mathrm{~mL}$ of small-particulate hyaluronic acid (patient also received botulinum toxin injection to the perioral area, depressor anguli oris, and mentalis muscles). (Picture courtesy of Timothy M. Greco, M.D.)

A
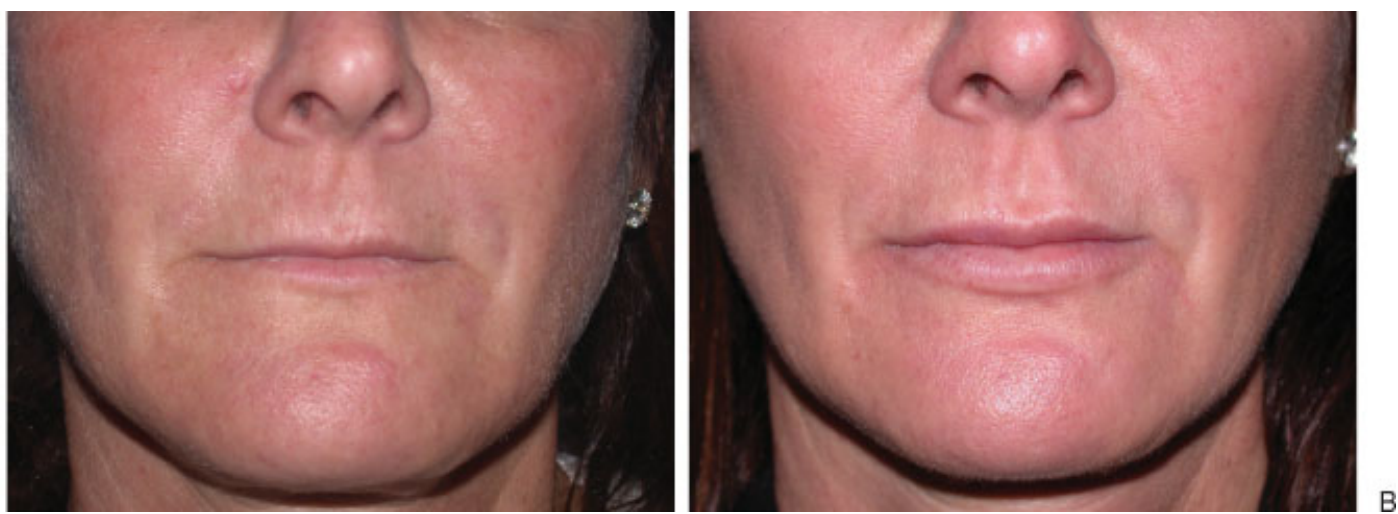

Figure 10 Volumization of the lips. (A) Pre- and (B) postinjection of $1.6 \mathrm{~mL}$ of nonparticulate hyaluronic acid. (Picture courtesy of Timothy M. Greco, M.D.)

vermilion border helps define the lip border and shape the lip line and allows for a better canvas to place lip liner. The tubercles of the lip (three on the upper lip and two on the lower lip), which correspond to the mesodermal units seen in the embryological development of these structures, are injected just anterior to the wet dry border. This provides plumpness and volume to the lip. Injection in the region of the gingivolabial sulcus just anterior to the attachment of the frenulum to the lip provides eversion of the lips. Cupid's bow may be accentuated with volumizing of the philtral columns with HA in linear threading fashion. As with all injections of HA fillers, manual molding immediately following injection is

A
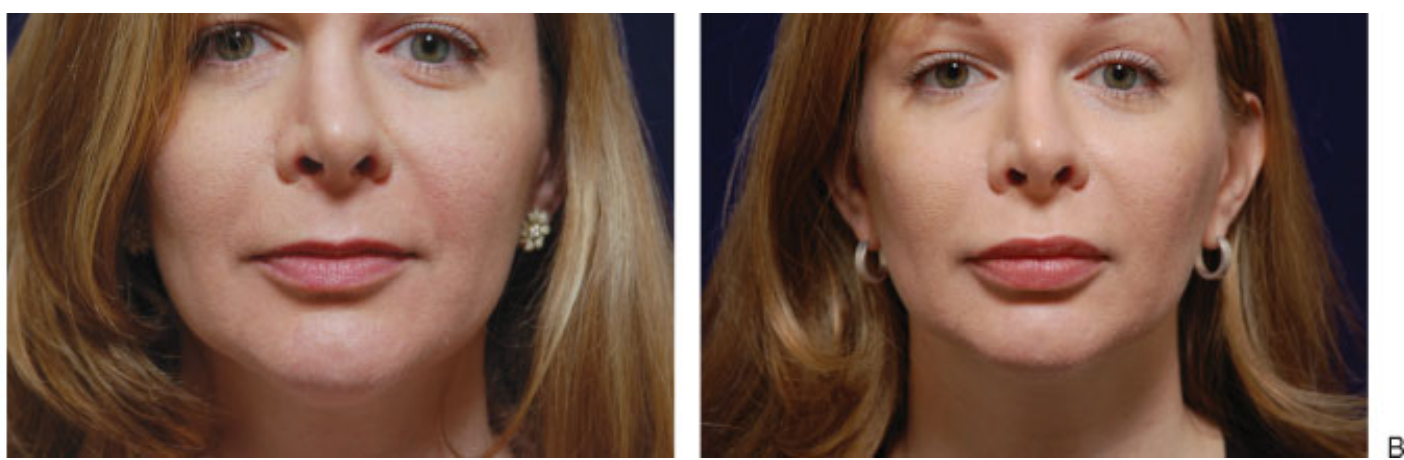

Figure 11 Volumization of the lips. (A) Pre- and (B) postinjection of $1.2 \mathrm{~mL}$ of nonparticulate hyaluronic acid (patient also received $0.8 \mathrm{~mL}$ of nonparticulate hyaluronic acid to the nasolabial fold). (Picture courtesy of Seth A. Yellin, M.D.) 

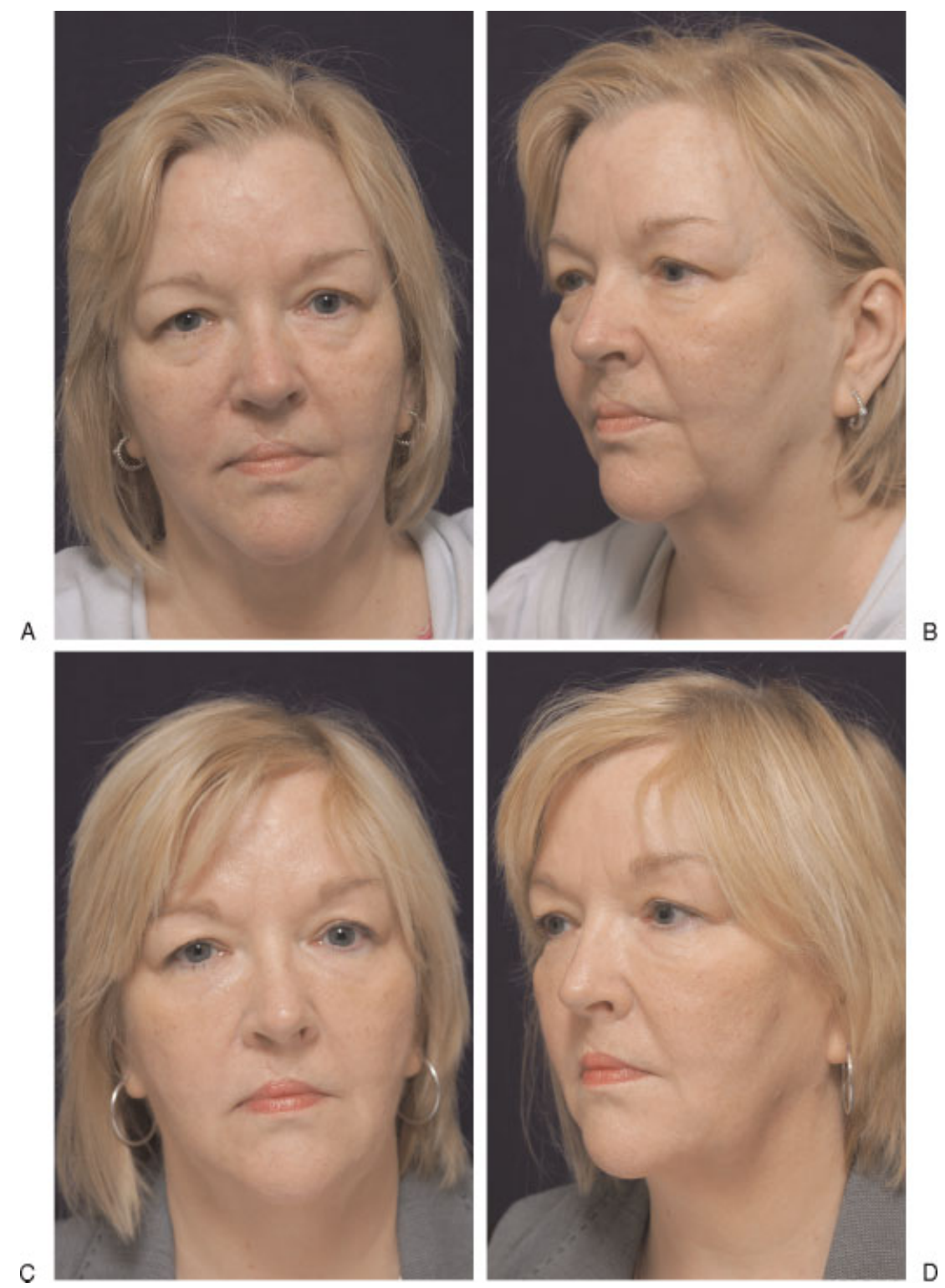

Figure 12 Volumization of the jawline. (A and B) Pre- and ( $C$ and D) postinjection of $2.3 \mathrm{~mL}$ of calcium hydroxylapatite to the marionette area and prejowl sulcus (patient also received $2 \mathrm{~mL}$ of small particulate hyaluronic acid to the tear trough). (Picture courtesy of Seth A. Yellin, M.D.)

critical to achieve a smooth and uniform result (-Figs. 10 and 11).

The final region of the lower one-third of the face that benefits from volumizing is the jawline, including the prejowl sulcus. The aging jawline is characterized medially by a prejowl depression or sulcus, followed by a jowl or mound, followed by a postjowl depression. All of the current fillers can be used to inflate the depressions in the region of the jawline to give a youthful mandibular line. When filling these areas in women, it is important to avoid creating a lower face that appears disproportionately heavy, which may masculinize the face. If the lower face and jawline are excessively lax, facial soft tissue repositioning with or without volumizing may help. When filling the mandibular areas, the senior authors favor a depot injection of HA,
CaHA, or PLLA placed supraperiosteally, supplemented with a linear threading technique subcutaneously, thus creating a layering effect. Regardless of the filler chosen, the initial volume is placed deep using the mandible as a platform. Volumizing of both the lateral and inferior aspects of the mandible in a three-dimensional manner yields the most satisfying result (-Figs. 12 and 13). Botulinum toxin to the masseter muscle in women can reduce muscle hypertrophy and lessen the square, masculine appearance while creating a softer, more oval look to the jawline. Injection of neurotoxin along the mandible and into the platysma can provide a subtle tightening to the jawline ("Nefirti lift"). ${ }^{57}$ This, along with volumizing the cheeks, helps to restore the heart-shaped appearance seen in the youthful face. 

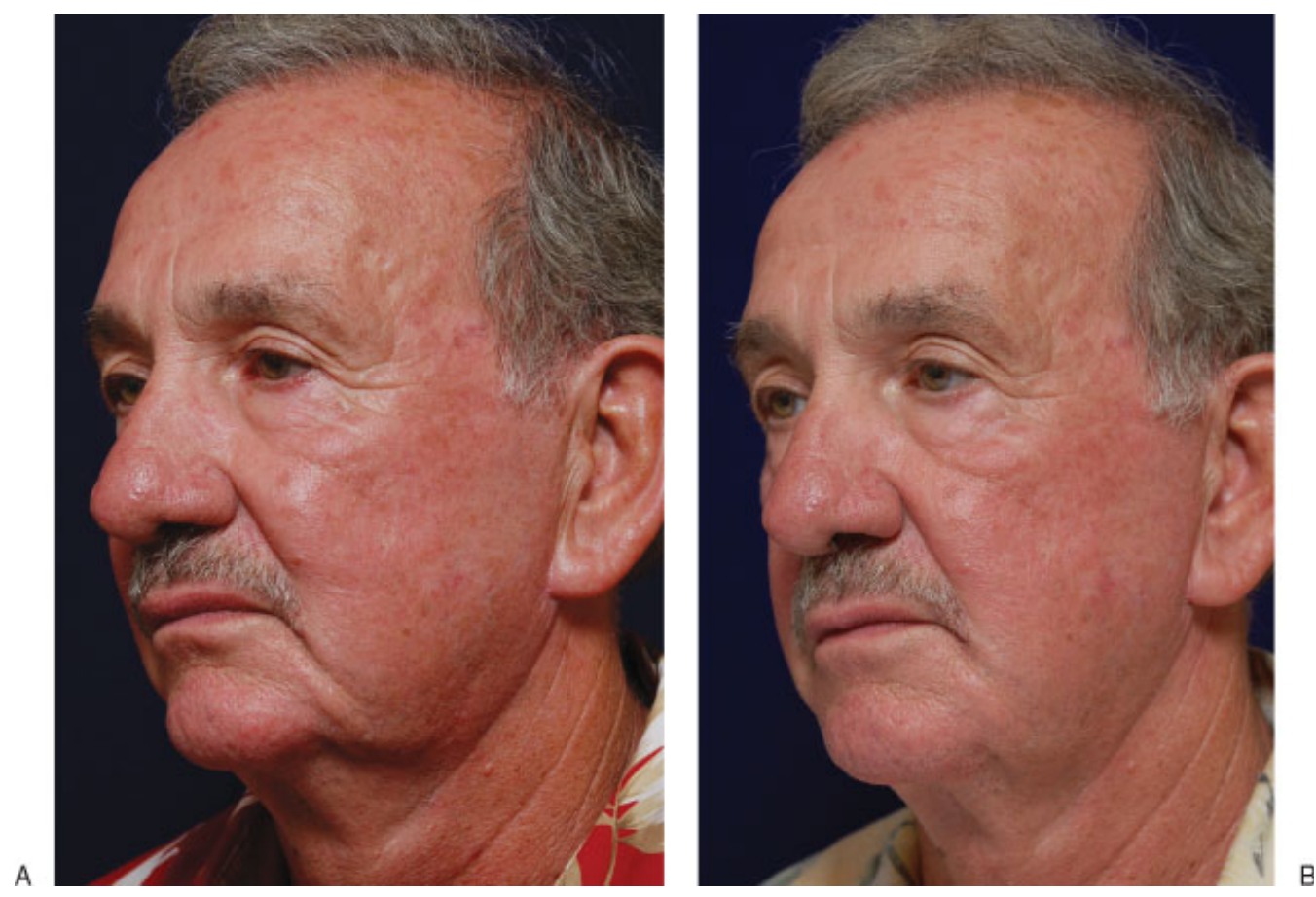

Figure 13 Volumization of the jawline. (A) Pre- and (B) postinjection of $3 \mathrm{~mL}$ of calcium hydroxylapatite to marionette area and prejowl sulcus. (Picture courtesy of Seth A. Yellin, M.D.)

\section{Conclusion}

Minimally invasive volumizing of the face utilizing off-theshelf fillers and/or biostimulators, either regionally or globally, supplemented with Botulinum toxin therapy where appropriate, can create a more youthful appearance and help correct some of the major changes associated with the aging process. In addition, these procedures can serve as a rehearsal to volumizing the face with structural fat grafting.

\section{References}

1 Pessa JE. An algorithm of facial aging: verification of Lambros's theory by three-dimensional stereolithography, with reference to the pathogenesis of midfacial aging, scleral show, and the lateral suborbital trough deformity. Plast Reconstr Surg 2000;106:479488; discussion 489-490

2 Rohrich RJ, Pessa JE. The fat compartments of the face: anatomy and clinical implications for cosmetic surgery. Plast Reconstr Surg 2007;119:2219-2227; discussion 2228-2231

3 Rohrich RJ, Pessa JE. The retaining system of the face: histologic evaluation of the septal boundaries of the subcutaneous fat compartments. Plast Reconstr Surg 2008;121:1804-1809

4 Lapière CM. The ageing dermis: the main cause for the appearance of "old" skin. Br J Dermatol 1990;122(Suppl 35):5-11

5 Greco TM, Elenitsas R. Localization and histological characterization of injected hyaluronic acid in excised nasolabial fold tissue. J Drugs Dermatol 2010;9:399-404

6 Lober CW, Fenske NA. Cutaneous aging: effect of intrinsic changes on surgical considerations. South Med J 1991;84:1444-1446

7 Hill WR, Montgomery H. Regional changes and changes caused by age in the normal skin. J Invest Dermatol 1940;3:231-245

8 Montagna W, Carlisle K. Structural changes in ageing skin. Br J Dermatol 1990;122(Suppl 35):61-70
9 Bolognia JL. Dermatologic and cosmetic concerns of the older woman. Clin Geriatr Med 1993;9:209-229

10 Gilchrest BA. Skin aging and photoaging: an overview. J Am Acad Dermatol 1989;21(3 Pt 2):610-613

11 Furnas DW. The retaining ligaments of the cheek. Plast Reconstr Surg 1989;83:11-16

12 Stuzin JM, Baker TJ, Gordon HL. The relationship of the superficial and deep facial fascias: relevance to rhytidectomy and aging. Plast Reconstr Surg 1992;89:441-449; discussion 450-451

13 Laurent TC. Biochemistry of hyaluronan. Acta Otolaryngol Suppl 1987;442:7-24

14 John HE, Price RD. Perspectives in the selection of hyaluronic acid fillers for facial wrinkles and aging skin. Patient Prefer Adherence 2009;3:225-230

15 Longas MO, Russell CS, He XY. Evidence for structural changes in dermatan sulfate and hyaluronic acid with aging. Carbohydr Res 1987;159:127-136

16 DeVore DP, Hughes E, Scott JB. Effectiveness of injectable filler materials for smoothing wrinkle lines and depressed scars. Med Prog Technol 1994;20:243-250

17 Tezel A, Fredrickson GH. The science of hyaluronic acid dermal fillers. J Cosmet Laser Ther 2008;10:35-42

18 Restylane $^{\circledR}$ (Package Insert). Scottsdale, AZMedicis Aesthetics Holdings, Inc.; 2010

19 JuveDerm ${ }^{\circledR}$ Ultra (package insert). Paris, France: Corneal; 2010

20 JuveDerm $^{\circledR}$ Ultra Plus (package insert). Paris, France: Corneal; 2010

21 Perlane $^{\circledR}$ (Package Insert). Scottsdale, AZ: Medicis Aesthetics Holdings, Inc.; 2010

22 Carruthers J, Carruthers A. A prospective, randomized, parallel group study analyzing the effect of BTX-A (Botox) and nonanimal sourced hyaluronic acid (NASHA, Restylane) in combination compared with NASHA (Restylane) alone in severe glabellar rhytides in adult female subjects: treatment of severe glabellar rhytides with a hyaluronic acid derivative compared with the derivative and BTX-A. Dermatol Surg 2003;29:802-809 
23 Rohrich RJ, Ghavami A, Crosby MA. The role of hyaluronic acid fillers (Restylane) in facial cosmetic surgery: review and technical considerations. Plast Reconstr Surg 2007;120:41-54

24 Friedman PM, Mafong EA, Kauvar AN, Geronemus RG. Safety data of injectable nonanimal stabilized hyaluronic acid gel for soft tissue augmentation. Dermatol Surg 2002;28:491-494

25 Fernández-Aceñero MJ, Zamora E, Borbujo J. Granulomatous foreign body reaction against hyaluronic acid: report of a case after lip augmentation. Dermatol Surg 2003;29:1225-1226

26 Lambros V. The use of hyaluronidase to reverse the effects of hyaluronic acid filler. Plast Reconstr Surg 2004;114:277

27 Marmur ES, Phelps R, Goldberg DJ. Clinical, histologic and electron microscopic findings after injection of a calcium hydroxylapatite filler. J Cosmet Laser Ther 2004;6:223-226

28 LeGeros RZ. Biodegradation and bioresorption of calcium phosphate ceramics. Clin Mater 1993;14:65-88

29 Lemperle G, Morhenn V, Charrier U. Human histology and persistence of various injectable filler substances for soft tissue augmentation. Aesthetic Plast Surg 2003;27:354-366; discussion 367

30 Misiek DJ, Kent JN, Carr RF. Soft tissue responses to hydroxylapatite particles of different shapes. J Oral Maxillofac Surg 1984;42: 150-160

31 Moers-Carpi MM, Tufet JO. Calcium hydroxylapatite versus nonanimal stabilized hyaluronic acid for the correction of nasolabial folds: a 12-month, multicenter, prospective, randomized, controlled, split-face trial. Dermatol Surg 2008;34:210-215

32 Moers-Carpi M, Vogt S, Santos BM, Planas J, Vallve SR, Howell DJ. A multicenter, randomized trial comparing calcium hydroxylapatite to two hyaluronic acids for treatment of nasolabial folds. Dermatol Surg 2007;33(Suppl 2):S144-S151

33 Felderman LI. RadiesseTM for facial rejuvenation. Cosmetic Dermatol 2005;18:823-826

34 Jacovella PF, Peiretti CB, Cunille D, Salzamendi M, Schechtel SA. Long-lasting results with hydroxylapatite (Radiesse) facial filler. Plast Reconstr Surg 2006;118(3, Suppl):15S-21S

35 Radiance FP. Facial Plast Surg 2004;20:165-169

36 Gogolewski S, Jovanovic M, Perren SM, Dillon JG, Hughes MK. Tissue response and in vivo degradation of selected polyhydroxyacids: polylactides (PLA), poly(3-hydroxybutyrate) (PHB), and poly(3-hydroxybutyrate-co-3-hydroxyvalerate) (PHB/VA). J Biomed Mater Res 1993;27:1135-1148

37 Sculptra ${ }^{\circledR}$ (Package Insert). Bridgewater, NJ: Sanofi-Aventis U.S., LLC; 2010

38 Moyle GJ, Brown S, Lysakova L, Barton SE. Long-term safety and efficacy of poly-L-lactic acid in the treatment of HIV-related facial lipoatrophy. HIV Med 2006;7:181-185

39 Lam SM, Azizzadeh B, Graivier M. Injectable poly-L-lactic acid (Sculptra): technical considerations in soft-tissue contouring. Plast Reconstr Surg 2006;118(3, Suppl):55S-63S

40 Lowe NJ. Optimizing poly-L-lactic acid use. J Cosmet Laser Ther 2008;10:43-46
41 Lacombe V. Sculptra: a stimulatory filler. Facial Plast Surg 2009; 25:95-99

42 Mest DR, Humble GM. Duration of correction for human immunodeficiency virus-associated lipoatrophy after retreatment with injectable poly-L-lactic acid. Aesthetic Plast Surg 2009;33: 654-656

43 Lowe NJ. Optimizing poly-L-lactic acid use. J Cosmet Laser Ther 2008;10:43-46

44 Borelli C, Kunte C, Weisenseel P, Thoma-Greber E, Korting HC, Konz B. Deep subcutaneous application of poly-L-lactic acid as a filler for facial lipoatrophy in HIV-infected patients. Skin Pharmacol Physiol 2005; 18:273-278

45 Haneke E. Polymethyl methacrylate microspheres in collagen. Semin Cutan Med Surg 2004;23:227-232

46 Lemperle G, Romano JJ, Busso M. Soft tissue augmentation with artecoll: 10-year history, indications, techniques, and complications. Dermatol Surg 2003;29:573-587; discussion 587

47 Hilinski JM, Cohen SR. Soft tissue augmentation with ArteFill. Facial Plast Surg 2009;25:114-119

48 Hoffmann C, Schuller-Petrovic S, Soyer HP, Kerl H. Adverse reactions after cosmetic lip augmentation with permanent biologically inert implant materials. J Am Acad Dermatol 1999;40: 100-102

49 Rudolph CM, Soyer HP, Schuller-Petrovic S, Kerl H. Foreign body granulomas due to injectable aesthetic microimplants. Am J Surg Pathol 1999;23:113-117

50 Jones DH, Carruthers A, Orentreich D, et al. Highly purified 1000cSt silicone oil for treatment of human immunodeficiency virusassociated facial lipoatrophy: an open pilot trial. Dermatol Surg 2004;30:1279-1286

51 Chasan PE. The history of injectable silicone fluids for soft-tissue augmentation. Plast Reconstr Surg 2007;120:2034-2040; discussion 2041-2043

52 Narins RS, Beer K. Liquid injectable silicone: a review of its history, immunology, technical considerations, complications, and potential. Plast Reconstr Surg 2006;118(3, Suppl): 77S-84S

53 Coleman SR. Structural fat grafting: more than a permanent filler. Plast Reconstr Surg 2006;118(3, Suppl):108S-120S

54 Pessa JE, Zadoo VP, Yuan C, et al. Concertina effect and facial aging: nonlinear aspects of youthfulness and skeletal remodeling, and why, perhaps, infants have jowls. Plast Reconstr Surg 1999;103: 635-644

55 Shaw RB Jr, Kahn DM. Aging of the midface bony elements: a threedimensional computed tomographic study. Plast Reconstr Surg 2007;119:675-681; discussion 682-683

56 Niamtu J III. Accurate and anatomic midface filler injection by using cheek implants as an injection template. Dermatol Surg 2008;34:93-95; discussion 96

57 Levy PM. The "Nefertiti lift": a new technique for specific recontouring of the jawline. J Cosmet Laser Ther 2007;9:249-252 